American Journal of Applied Sciences 8 (5): 499-507, 2011

ISSN 1546-9239

(C) 2010 Science Publications

\title{
Quality Measurements on the Radio Interface of the Mobile Communication in the Proximity of the Power System
}

\author{
${ }^{1}$ Said Ghnimi, ${ }^{1}$ Adnen Rajhi, ${ }^{1}$ Ali Gharsallah and ${ }^{2}$ Fakhreddine Khlifa \\ ${ }^{1}$ Department of Physics, Faculty of Science, Tunis El Manar 2092, Tunisia \\ ${ }^{2}$ Telecommunications Center CERT, City of Technology, Tunisia
}

\begin{abstract}
Problem statement: The electric power lines and its associated equipments generally produce an electromagnetic noise in their environment, which are likely to have dangerous effects on propagation environment to the Global System for Mobile communication (GSM) cellular mobile network. Approach: In this study, we analyzed the characteristics of the power line noise and its correlation with the GSM burst; showing that the considered noise source to the Mobile Station (MS) and Base Transceiver Station (BTS) of GSM system is due to the presence of fundamentals and harmonics fields (electric and magnetic fields) in the proximity of power lines functioning at the permanent state; specially the present of the 5th harmonic field which is close to the GSM pulsed field at the frequency $217 \mathrm{~Hz}$. Results: This study shows the measurements and analysis results for QoS of GSM network based on the GSM metrics such as Mobile Station Power (MSP), Received signal power level (RxLevl), Received signal quality (RxQual), Carrier to Interference ratio (C/I) and Frame Error Rate (FER). These experiments were done inside and outside an area of $50 \mathrm{~m}$ distance from the tower of power line and take on consideration the two real situations (in the case of the absence of BTS and in the case of the presence of the BTS inside an area of radius $50 \mathrm{~m}$ around the power line). Conclusion/Recommendations: The experimental results in idle and dedicated mode are more important and it has been observed that the influence of this noise produced by these power lines leading to a degradation of the MSP, RxLev and RxQual respectively with an important FER.
\end{abstract}

Key words: Propagation environment, Quality of Service (QoS), Base Transceiver Station (BTS), Mobile Station Power (MSP), Received signal power Level (RxLevl), Received signal Quality (RxQual), Frame error rate, Nemo outdoor, Power line

\section{INTRODUCTION}

The GSM network transmission quality is an important topic in the public and professional environments. The influence of these propagation environments to the GSM cellular mobile network are widely used by many authors in the real-time requirements of mobile telecommunication systems (Hata, 1980; Capsoni et al., 2009; Athanasiadou et al., 2000; Anderson, 2003; Abhayawardhana et al., 2005; Tan et al., 2003; Low, 1992; Jawhar and Wu, 2005; Chen et al., 2005; Srivastava and Mishra, 1997; Ronchini and Gaiani, 1998; Tunnicliffe et al., 1997; Sathyendranl and Smith, 1998; Silventoinen et al., 1997; Islam et al., 2006; Ismail et al., 2010; www.anite.com/nemo). Different propagation models are used extensively in GSM network planning and can be broadly categorised into three types models respectively, empirical, deterministic and stochastic (Hata, 1980; Capsoni et al., 2009; Athanasiadou et al.,
2000; Anderson, 2003). The first model is based on observations and measurements alone and this model is mainly used to predict the path loss, but models that predict rain-fade and multipath have also been proposed by (Hata, 1980) and evaluated by (Singh et al., 2006). The second make use of the laws governing electromagnetic wave propagation to determine the received signal power at a particular location (Capsoni et al., 2009) and the third; often require a complete 3-D map of the propagation environment (Athanasiadou et al., 2000). These models are also very useful for performing interference and coupling studies as the deployment proceeds particularly for conducting feasibility studies during initial deployment requiring the least information about the environment (Abhayawardhana et al., 2005; Tan et al., 2003). The European research committee COST 231 has developed a new propagation model for the estimation of urban transmission loss in cellular mobile radio (Low, 1992), this model considers the diffraction loss due to

Corresponding Author: Said Ghnimi, Department of Physics, Faculty of Science, Tunis E1 Manar 2092, Tunisia 
equidistantly spaced buildings, the direct radio path and scatter losses from the roof-top down to the mobile.

The diversity of these models is used to analyse the performance of the quality of service of GSM mobile network for different environments. The research for QoS support in TDMA-based mobile networks at the different layers of the networking model is presented and analysed (Jawhar and $\mathrm{Wu}, 2005)$. Chen et al. (2005), proposed a scalable framework Q-GSM for service management in grid environments, to meet the requirements of both grid users and service providers. Srivastava and Mishra (1997), addressed the choices needed to be made in the design of a quality of service framework for mobile and wireless networks.

Different contributors have studied the performance of the GSM networks characteristics from the frequency and power point of view. In one hand; the frequency hopping and discontinuous transmission are techniques that can be adopted in order to improve performance of mobile communication system; the former exploits the frequency and interference diversity, the latter through the increase of spectral efficiency due to the reduction of interference during silent periods (Ronchini and Gaiani, 1998). Tunnicliffe et al. (1997), investigates the performance of GSM systems employing slow frequency hopping when a limited number of hopping channels are used. Sathyendranl and Smith (1998), presents a theoretical method to study the performance improvement in GSM networks due to slow frequency hopping when a limited number of hopping channels are available. On the other hand; Baseband frequency hopping in the combination with downlink power control and discontinuous transmission has been investigated as a quality improving feature in a live GSM network. Using the dropped call rate and the frame erasure rate to measure the network quality, the use of frequency hopping proves a powerful network quality enhancement feature. Silventoinen et al. (1997), investigates the usage of fast power control in global system for mobile communications based Home Base Station (HBS) system to alleviate Rayleigh fading for slow moving Mobile Stations (MS). These various applications provide different services with high and important qualities. Several ways to measure GSM network performance have been described. Although the evaluation of the QoS management performance of this network is difficult due to the environment complexity, the goal of our study was the measurement of a QoS for GSM network components in the vicinity of the electric power lines. In our approach, we measured the performance of the GSM transmission quality through soft mechanisms Nemo Outdoor air interface measurement tool (www.anite.com/nemo) installed in the drive testing equipment for two scenarios of measurements; in the case of the absence and presence of the BTS inside an area of radius $50 \mathrm{~m}$ around the power line. The purpose of our study is to make the measurement of the QoS to validate the theoretical results of the GSM signal deformation by the noise due to the power line system and verified the results of a study of second reflection effects of high voltage transmission line on HF antenna radiation characteristic by scaling model (Kesheng et al., 1997). The methodology of measurement for cellular communication networks is based on the data collected through drive testing; it is focused on the end user perception of service quality and it is independent of access technologies implemented by the cellular networks. This system allows us to objectively evaluate the requirements of network applications for delivering user acceptable quality (Beuran et al., 2003; Kostanic et al., 2009).

In this study, we describe the influence of propagation environment in a GSM signal and its performance indices in idle and dedicated mode. In addition, we confirm the correlation of the degradation of transmission quality with the presence of noise generated by the electrical power lines through measurements of the quality of service in a real situation.

\section{MATERIALS AND METHODS}

Statement of the problem: The diversity of the mobile telecommunication systems raises questions about the criteria chosen by these operators for the installation of their own networks with the electrical power network which represents the source of excitation of these networks:

- The notions of electromagnetic compatibility are they taken into account?

- Which are the international standards used on this level? Knowing that until present there is an absence of the standards of the electrical power network with respect to the mobile telecommunications network

To study this problem, we have used two measurements procedure in order to predict the transmission quality of GSM network in the presence of the electromagnetic disturbances. These two 
methodologies converge generally towards the search for two criteria:

- The first consists in defining the characteristics of the two systems to establish tolerance levels defined by international standards

- The second chooses a predictive step to study the appearance of a coupling in permanent state

Table 1 defining the characteristics of the two Systems respectively; the source is the power lines and the victim is GSM network.

The coexistence of the power lines and network GSM within same environment entrains a problem of coupling, but the questions which arise are:

- What is the nature of this coupling knowing that the characteristics of two systems are different?

- We suggest that the nature of this coupling is electromagnetic. What are the averages used to study the phenomena of disturbance?

The GSM mobile phones transmitted and received with the base station using a Time Division Multiple Access (TDMA) channel structure at different eight time slots (Fig. 1). The RF burst, which transmitted approximately 156.25 bits during $577 \mu \mathrm{s}$, is transmitted periodically every length frame $4.615 \mathrm{~ms}$; this repetition rate results into a pulsed EM field at the frequency of $217 \mathrm{~Hz}$. This pulsed modulated field pattern is repeated in the RF transmission for each of the eight time slots in the frame.

The quality of service of GSM network depends on the influence of propagation environment on the frame and due to the complexity of these environments, the erroneous received bits tend to appear in "bursts".

In this study, we have studied the correlation between the noise generated by the electric power line and the signal transmitted by GSM network. In this context, we have investigated the experimental measurements quality of GSM signal in the vicinity of the electric power line system.

Description of the measuring scenarios setup: The measurements are carried out in a specific area (RadèsTunisia) according to two different scenarios. In the first scenario; we chose to make measurements on network GSM, close to the power lines and in the absence of base station near these lines. While the second scenario is similar to the first except that in this time a base station is present near these lines.

Table 1: Characteristics of source and victim

\begin{tabular}{ll}
\hline Characteristic of the power lines & Characteristic of GSM network \\
\hline Voltage level: HT/MT $(150 \mathrm{kV} / 33 \mathrm{kV})$ & Voltage level: BT $(220 \mathrm{v})$ \\
Frequency: $\mathrm{LF} 50 \mathrm{~Hz}$ & Frequency: HF [890-960 MHz] \\
Role: Transport electric power & Role: Transmission of information \\
EM Quasi-static environment. & EM Environment ultra high frequency pulsated with $217 \mathrm{~Hz}$ \\
Standard: Limits of exposure of the public recommended by the & Standard: Limits of exposure of the public recommended by \\
CIPRNI $(\mathrm{E}=5000 \mathrm{~V} / \mathrm{m}, \mathrm{B}=100 \mathrm{mT})$ & the CIPRNI $\left(\mathrm{J}=4.5 \mathrm{w} \mathrm{m}^{-2}\right)$ \\
\hline
\end{tabular}

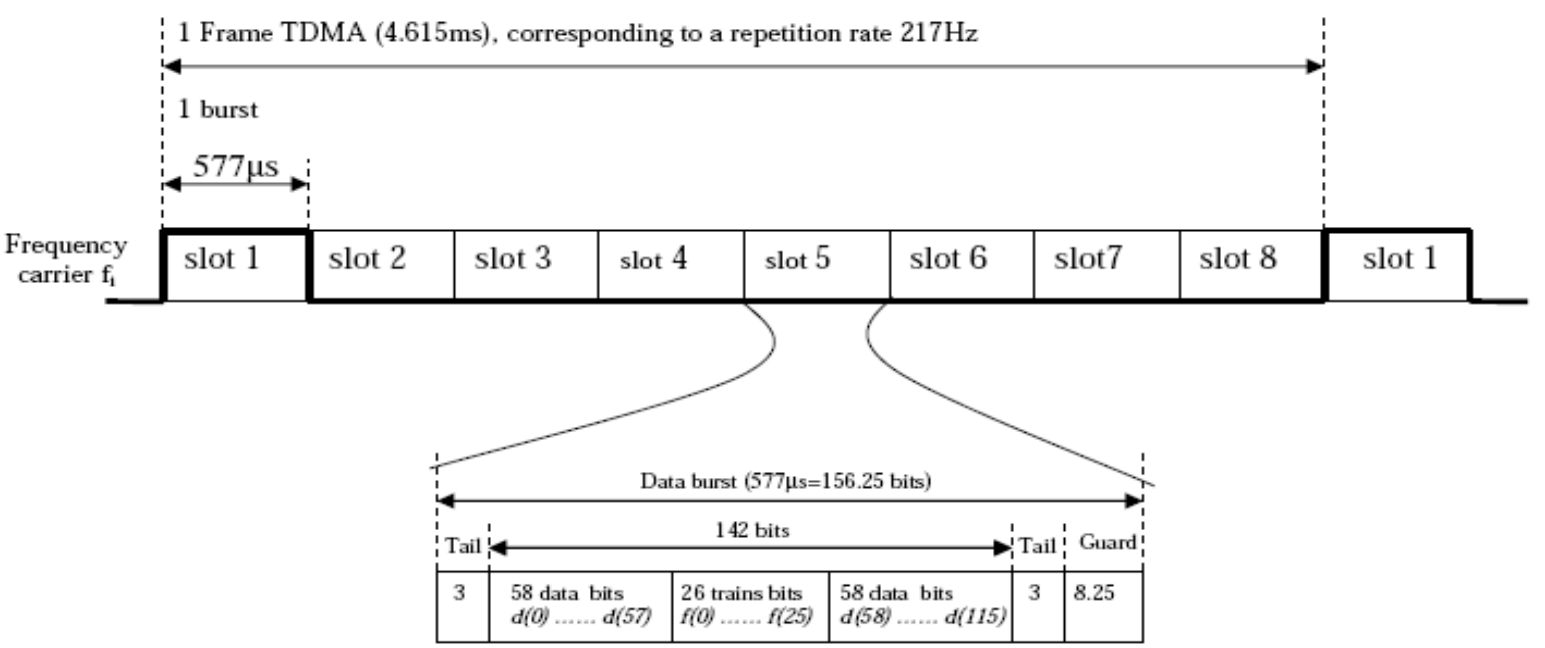

Fig. 1: The GSM frame structure with envelope signal $(217 \mathrm{~Hz})$ 
Am. J. Applied Sci., 8 (5): 499-507, 2011

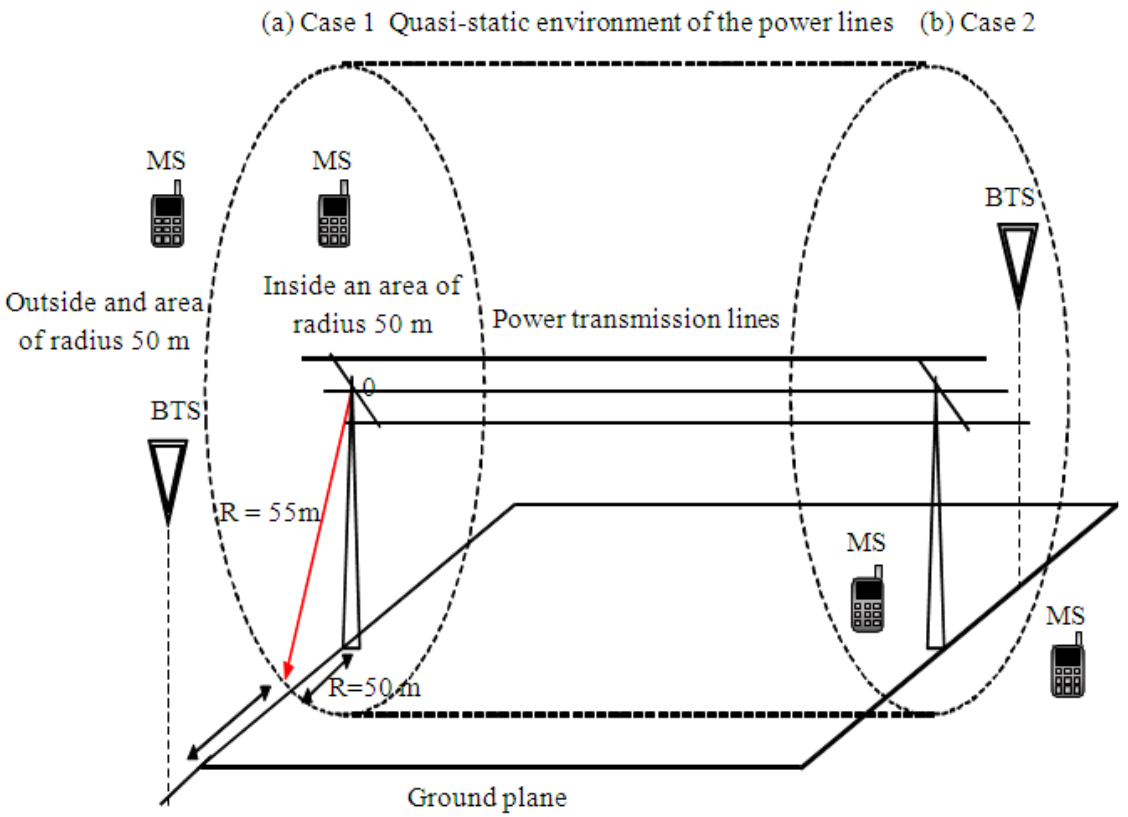

Fig. 2: Different scenarios from measurement: (a) without BTS, (b) in the presence of a BTS

Table 2: RxQual and FER

\begin{tabular}{ll}
\hline Value if RxQual & Interval of FER in \% \\
\hline 0 & $<4.5$ \\
1 & {$[4.5,8.5]$} \\
2 & {$[8.5,12.5]$} \\
3 & {$[12.5,16.5]$} \\
4 & {$[16.5,20.5]$} \\
5 & {$[20.5,24.5]$} \\
6 and 7 & $>24.5$ \\
\hline
\end{tabular}

As it was shown in previous results, the limits of the electric and magnetic fields do not exceed a radius of $50 \mathrm{~m}$ around the power transmission lines and we also studied the behavior and the distribution of these fields around the area of $50 \mathrm{~m}$. In this part, our objective consists in studying the correlation of these fields (fundamentals and harmonic fields), due to the power lines, with the electric radio signals obstructed by network GSM inside and outside these zones of measurements (Fig. 2).

It is well know that the GSM network uses different parameters to describe the quality of a channel:

- The received power by the mobile station (RxLEv): This indicator is measured by MS, every 0.5 second. The measured power average is given by the below Eq. 1:

$$
\operatorname{RxLev}=\frac{1}{\mathrm{M}} \sum_{\mathrm{i}=1}^{\mathrm{M}} \mathrm{P}_{\mathrm{r}_{\mathrm{i}}}
$$

Where:

$\mathrm{M}=$ The number of measured sample

$\mathrm{P}_{\mathrm{r}_{\mathrm{i}}}=$ Received measured sample power by the mobile station

- $\quad$ The Mobile Station Power (MSP): This parameter is transmitted power of signal used by mobile station and it is controlled by the BS station with a power control algorithm

- The Received Signal Quality (RxQual): The RxQual parameter is calculated from the Frame Error Rate (FER) parameter and it is expressed in percent and calculated before error correction following the below Eq. 2:

$\mathrm{FER}=\frac{1}{\mathrm{~N}} \sum_{\mathrm{i}=1}^{\mathrm{N}} \mathrm{x}_{\mathrm{i}}$

Where:

$\mathrm{x}_{\mathrm{i}}=0=$ If the transmitted frame is received correctly

$\mathrm{x}_{\mathrm{i}}=1=$ Otherwise

$\mathrm{N}=$ The total number of transmitted frame

The RxQual value is obtained by the following Table 2 . 


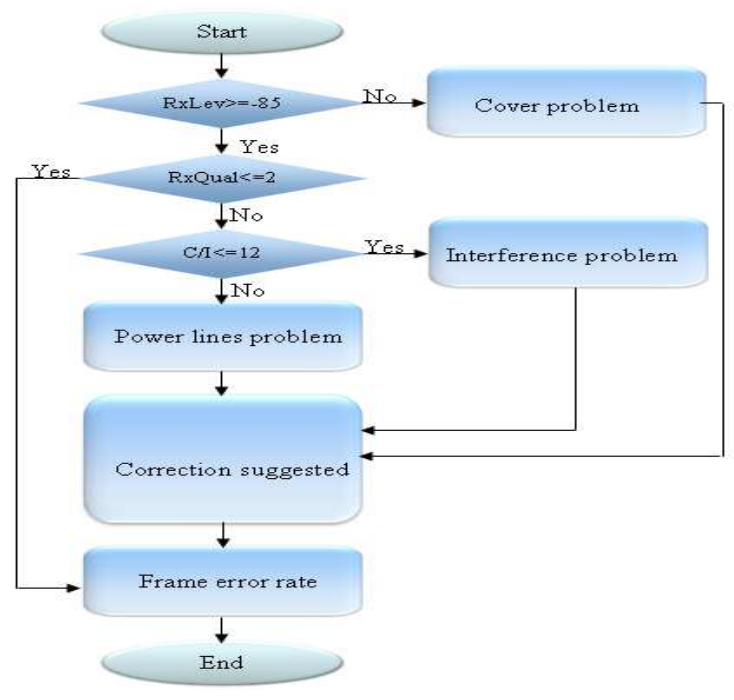

Fig. 3: Proposed algorithm

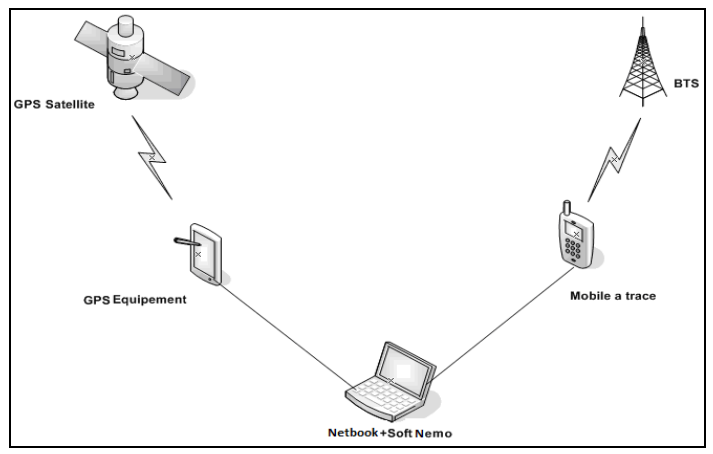

Fig. 4: Measuring equipment

- The carrier to interference ratio $(\mathrm{C} / \mathrm{I})$ : This parameter is used to determine the level of interference of useful signal. The following formula is used to calculate $\mathrm{C} / \mathrm{I}$ indicator Eq. 3:

$C / I=10 \log _{10} \frac{\left|P_{u}\left(f_{j}, t\right)\right|}{\sum_{i=1, i \neq u}^{U}\left|P_{i}\left(f_{j}, t\right)\right|}$

Where:

$\mathrm{P}_{\mathrm{u}}\left(\mathrm{f}_{\mathrm{j}}, \mathrm{t}\right)=$ The useful power of received signal modulated by the $f_{i}$ frequency

$\mathrm{P}_{\mathrm{i}}\left(\mathrm{f}_{\mathrm{j}}, \mathrm{t}\right)=$ The interferer signal emitted by other base station and use the same frequency $f_{j}$

The measurements of these parameters such as RxLev, FER, C/I, RxQual and MSP are given by the equipments of the drive test using the NEMO outdoor platform shown in Fig. 4.
The protocol of measurement is based at the same time on the measurement accessibility to the network, on the measurement of the field level and on the establishment of the real communications. These measurements can be gathered in two modes respectively: Measurements with the idle and in a dedicated state of the mobile station.

In the first mode, the communication is done in the direction going down (downlink), where the base station emitted on BCCH channels. The mobiles communicate with the BTS via these channels. On the other hand, in the second mode (in dedicated mode), the mobile makes a communication in the two directions (uplink and downlink) with the BTS with the help of a channel $\mathrm{TCH}$ and the other channels of indication, mainly the $\mathrm{BCCH}$.

Once measurements are carried out, we use an algorithm of analysis of these measurements (Fig. 3), in order to determine the various possible problems which can emerge and which affect the quality of service offered by the GSM network.

\section{RESULTS}

Idle mode: In the development of these measurements we used a plate form of measurement Nemo Outdoor (www.anite.com/nemo). In this mode of measurement, this tool enabled us to measure the various signals and indication exchanged between GSM mobile and the BTS. For better seeing the follow-up of the tracing, it is enough to zoomer the starting point, its name and its sectorization. Among the measured indicators; the received signal level (RxLev) at any point of measurement which is represented in Fig. 5, showing the distribution of the signal level of each measurement point.

When we leave the radius $50 \mathrm{~m}$, the signal level improves and consequently all these results make it possible to conclude that there is an indication of a correlation between GSM network and power transmission lines.

Dedicated mode: With the difference of the first mode (idle mode), of this measurement mode, one establishes a call towards a vocal server. For this fact, one used the same measuring equipment which enabled us to raise a group of indicators: MSP, RxLev, RxQual, FER and C/I.

The Fig. $6 \mathrm{a}$ and $\mathrm{b}$ represent the parameters defined above.

The Fig. $7 \mathrm{a}$ and $\mathrm{b}$ give inductions on parameter $\mathrm{C} / \mathrm{I}$ and show measurements on the interference under the same preceding conditions. 
Am. J. Applied Sci., 8 (5): 499-507, 2011

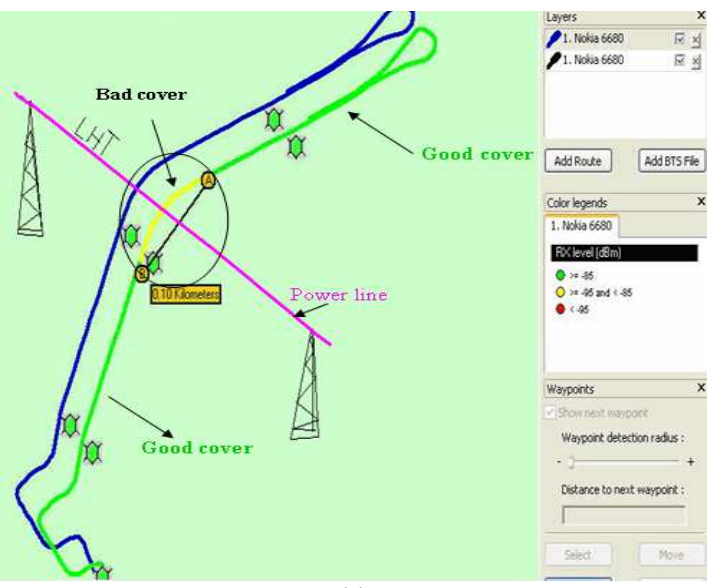

(a)

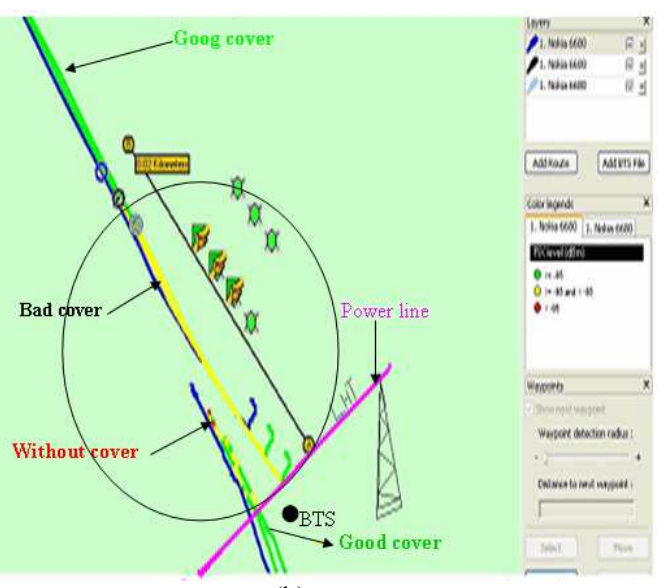

(b)

Fig. 5: Course of measurement of the signal level of the visited area: (a) without BTS, (b) in the presence of a BTS
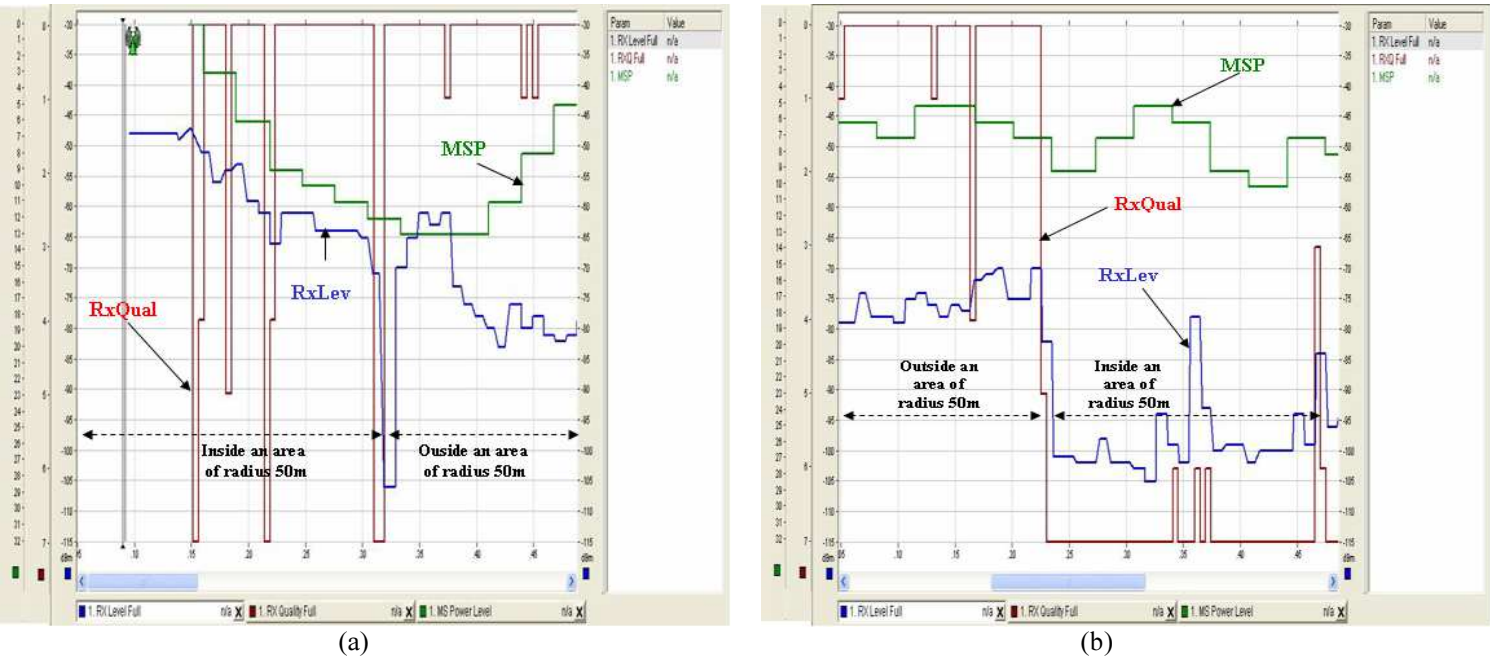

Fig. 6: Quality of service in the visited area: (a) without BTS, (b) and in presence of a BTS

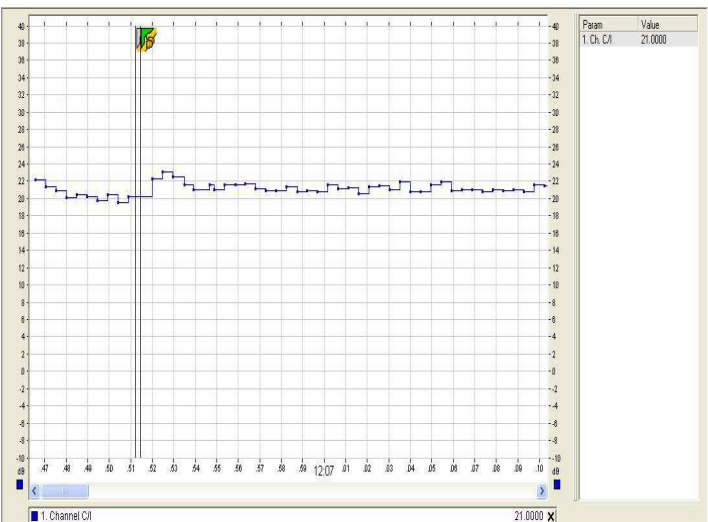

(a)

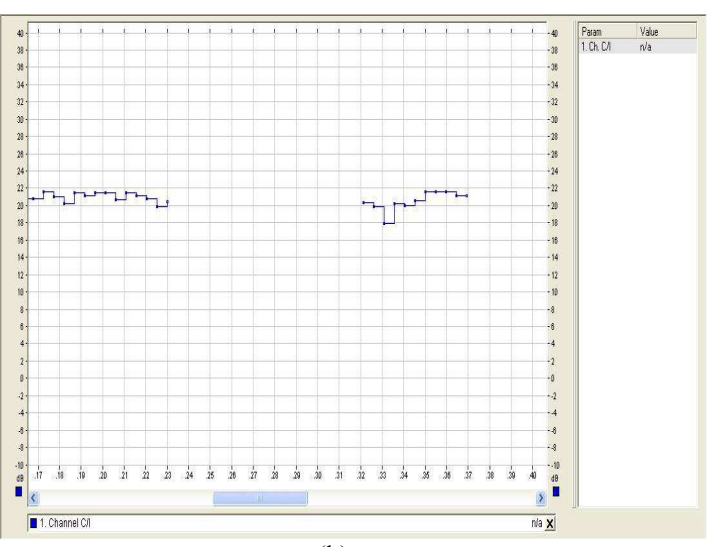

(b)

Fig. 7: The interference Level of the visited area (a) without BTS, (b) and in presence of a BTS 


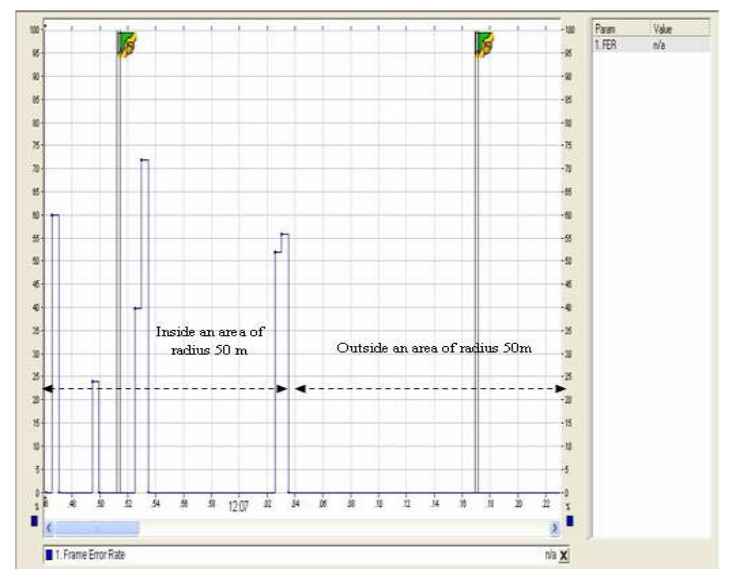

(a)

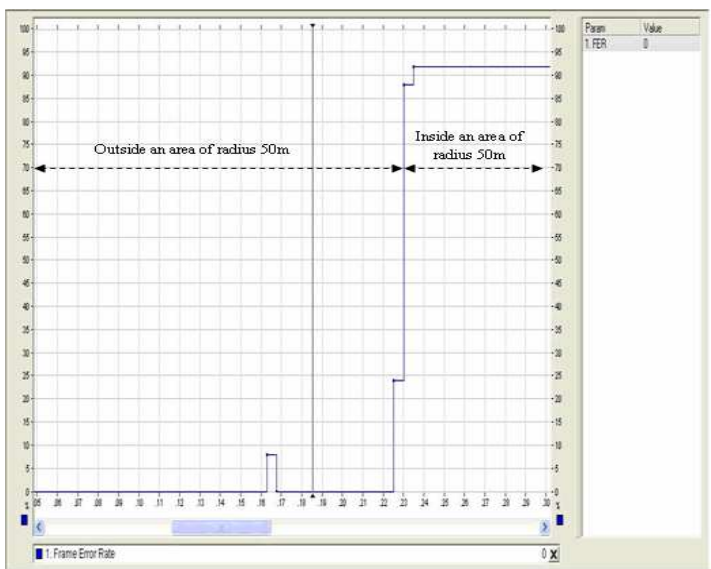

(b)

Fig. 8: The Level of frame error rate of the visited area: (a) without BTS, (b) and in presence of a BTS

The FER parameter is presented in the Fig. $8 \mathrm{a}$ and b. These results and these observations are they in conformity with the theoretical results which we already mentioned?

\section{DISCUSSION}

In the first case of measurements, we notice that the weakening of the signal level in a radius of $50 \mathrm{~m}$ around the power line is more significant than that of the second case. And that can be justified by the presence of a tri-sectorized BTS very close to the power line. In this case, the level of the emitted signal will be more significant, the power line influences just the sector of a BTS opposite this line. Indeed, the BTS provided permanently a maximum of power towards GSM mobile, the power lines generate electric and magnetic fields taking the form of a disturbing power. Two cases are studied: On the one hand, when GSM mobile moves away from the BTS, the power provided by this last decreases according to the distance. The convolution of this low power with the disturbing power influences on the signal level provided by this network. In addition, when the mobile station is near to the BTS, one notes that GSM mobile receives a raised power, by consequence, the influence of these lines on the signal level is proven just in the disturbed sector, on the contrary; in the other sectors, the BTS ensures a good cover of the network.

When we leave the radius $50 \mathrm{~m}$, the signal level improves and consequently all these results make it possible to conclude that there is an indication of a correlation between GSM network and power transmission lines.
The Fig. 6a shows the first case where the BTS misses in the area of radius $50 \mathrm{~m}$ around a power line. In this case, we notice that the signal level presents a good cover of the network, with a bad quality of signal (RxQual). Indeed, in our case, the adequate parameter setting of the handover makes it possible the mobile station to change cell when this is necessary: Following the weakening of the signal level between the BTS and the MS in idle mode, the GSM mobile finds another base station in another cell able to ensure the communication under the best conditions. Therefore the technique of handover in dedicated mode makes it possible to optimize the signal level and does not guarantee a good quality of the signal provided by this network. This explains why the noises generated by the influential power lines on the received electromagnetic signal in GSM mobile.

On the other hand and in the second case, where the BTS is located in the area of radius $50 \mathrm{~m}$ around the power lines (Fig. 6b), one notes practically the same results in the same area, but the quality of signal becomes very bad compared to the first case. Concerning the mobile station power, one notes, also, that when one moves away from the base station, the power of the mobile is too disturbed (Fig. 6a), which influences negatively the recovery of received signal by this GSM mobile.

Practically for the two cases of figure and in the area of radius $50 \mathrm{~m}$ around the power lines, the degradations are remarkable as well for the level of field, as for the quality of the signal. Apart from this area, GSM network presents a good cover of network with a very good quality of signal and almost stable power, therefore the signal of this network returns in 
a normal state. One can note holes of cover caused by the power lines.

We wanted to deepen the analysis to confirm the observation that there is an effect of the power lines on GSM network. For this fact, a study based on parameter $\mathrm{C} / \mathrm{I}$ is necessary. In fact, one wanted to see whether it is a problem of interference due to GSM network and more precisely to the re-use of the frequencies.

The two Fig. $7 \mathrm{a}$ and $\mathrm{b}$ show that the indicator $\mathrm{C} / \mathrm{I}>$ 12 , what confirms that there is no interference on the received signal.

The presented discontinuity in the Fig. $7 \mathrm{~b}$ due to the strong disturbances of the power lines which generate intensive noises induced in the mobile, justifies the correlation between these power lines and the problems appearing in GSM network.

It is concluded finally that the power line is the source of this disturbance of GSM signal in the case of presence or absence of the base station.

This disturbance touches also the component of GSM signal. A bad quality of the signal implies a strong probability of error in a frame.

The experimental results presented in the Fig. 8a and $\mathrm{b}$, prove a strong probability of error in the vicinity of the power lines especially in the radius of $50 \mathrm{~m}$ of the power line and the base station is near to $20 \mathrm{~m}$ compared to the line. When one moves far from this radius, the FER decreases according to the distance.

The experimental study that we carried out in this study on the frame error rate coincides with the theoretical results. Indeed, more the level of the fields is high in the cells where there are power lines, the quality of the signal is more degraded and FER increases and when we move far from an area of radius $50 \mathrm{~m}$ around the power lines, the GSM network returns to its stable state.

\section{CONCLUSION}

This study presents the measurement and analysis of GSM transmission quality in the vicinity of the power lines for two cases studies. The experimental results consolidate the correlation between the degradation of the performance of this transmission quality and the disturbed environment due to the power lines which generates the intensive noise in permanent state. The type of the noise can be considered by the presence of the harmonic and fundamental fields affecting the envelope of the burst and can affect the GSM network equipments.

According to the results which we found, we recommend that the distance limit of the power lines disturbing fields to the radio mobile propagation environment is approximately 50 meters. Instead, it is proposed that further in depth work to fox in the study the possible solutions to decrease the disturbance in the GSM radio mobile environment.

\section{REFERENCES}

Abhayawardhana, V.S., I.J. Wassell, D. Crosby, M.P. Sellars and M.G. Brown, 2005. Comparison of empirical propagation path loss models for fixed wireless access systems. Proceedings of the IEEE 61st Vehicular Technology Conference, May 30-01 June, IEEE Xplore Press, UK., pp: 73-77. DOI: 10.1109/VETECS.2005.1543252

Anderson, H.R., 2003. Fixed Broadband Wireless System Design. 1st Edn., John Wiley and Co., UK., ISBN: 0470844388, pp: 510.

Athanasiadou, G.E., A.R. Nix and J.P. McGeehan, 2000. A microcellular ray-tracing propagation model and evaluation of its narrow-band and wideband predictions. IEEE J. Selected Areas Commun. Wireless Commun., 18: 322-335.

Beuran, R., M. Ivanovici and B. Dobinson, 2003. Network quality of service measurement system for application requirements evaluation. Bedford, NH USA.

Capsoni, C., L. Luini, A. Paraboni, C. Riva and A. Martellucci, 2009. A new prediction model of rain attenuation that separately accounts for stratiform and convective rain. IEEE Trans. Antennas Propagat., 57: 196-204. DOI: 10.1109/TAP.2008.2009698

Chen, H., H. Jin, F. Mao and H. Wu, 2005. Q-GSM: QoS oriented grid service management. Web Technol. Res. Devel. APWeb, 3399: 1041-1044. DOI: 10.1007/978-3-540-31849-1_102

Hata, M., 1980. Empirical formula for propagation loss in land mobile radio services. IEEE Trans. Vech. Technol., 29: 317-325. DOI: 10.1109/TVT.1980.23859

Islam, M.R., O.O. Khalifa, L. Ali, A. Azli and M. Zulkarnain, 2006. Radiation measurement from mobile base stations at a university campus in Malaysia. Am. J. Applied Sci., 3: 1781-1784. DOI: 10.3844/ajassp.2006.1781.1784

Ismail, A., N.M. Din, M.Z. Jamaludin and N. Balasubramaniam, 2010. Mobile phone base station radiation study for addressing public concern. Am. J. Eng. Applied Sci., 3: 117-120. DOI: 10.3844 /ajeassp.2010.117.120

Jawhar, I. and J. Wu, 2005. QoS support in TDMAbased mobile ad hoc networks. J. Comput. Sci. Technol., 20: 797-810. DOI: 10.1007/s11390-0050797-3 
Kesheng, Z., Z. Linchang and Y. Wei, 1997. A study of second reflection effects of high voltage transmission line on $\mathrm{HF}$ antenna radiation characteristic by scaling model. Proceedings of the IEEE International Symposium on Electromagnetic Compatibility, May 21-23, IEEE Xplore Press, Beijing, China, pp: 413-416. DOI: 10.1109/ELMAGC.1997.617177

Kostanic, I., N. Mijatovic and S.D. Vest, 2009. Measurement based QoS comparison of cellular communication networks. Proceedings of the IEEE International Workshop Technical Committee on Communications Quality and Reliability, May 1214, IEEE Xplore Press, Naples, FL, pp: 1-5. DOI: 10.1109/CQR.2009.5137360

Low, K., 1992. Comparison of urban propagation models with $\mathrm{CW}$-measurements. Proceedings of the IEEE 42nd Vehicular Technology Conference, May 10-13, IEEE Xplore Press, Denver, CO, USA., $\quad$ pp: 936-942. DOI: 10.1109/VETEC.1992.245273

Ronchini, M.C. and E. Gaiani, 1998. Improvement of GSM system performance due to frequency hopping and/or discontinuous transmission. Proceedings of the IEEE International Conference on Communications, Jun. 7-11, IEEE Xplore Press, Atlanta, GA, USA., pp: 1596-1600. DOI: 10.1109/ICC.1998.683093

Sathyendranl, A. and P.J. Smith, 1998. A theoretical study of the performance improvement in GSM networks due to slow frequency hopping. Proceedings of the 48th IEEE Vehicular Technology Conference, May 18-21, IEEE Xplore Press, Ottawa, Ont., Canada, pp: 2207-2211. DOI: 10.1109/VETEC.1998.686149
Silventoinen, M.I., P.A. Ranta and M. Raitola, 1997. Fast power control for GSM HBS using training sequences. Proceedings of the 47th IEEE Vehicular Technology Conference, May 4-7, IEEE Xplore Press, Phoenix, AZ, USA, pp: 1689-1693. DOI: 10.1109/VETEC.1997.605846

Singh, M.S.J., S.S.I. Hassan, M.F. Ain, F.K. Ghani and K. Tanaka et al., 2006. Earth-to-space improved model for rain attenuation prediction at ku-band. Am. J. Applied Sci., 3: 1967-1969. DOI: 10.3844/ajassp.2006.1967.1969

Srivastava, M. and P.P. Mishra, 1997. On quality of service in mobile wireless networks. Proceedings of the 7th IEEE International Workshop on Network and Operating System Support for Digital Audio and Video, May 19-21, IEEE Xplore Press, St. Louis, MO, USA., pp: 147-158. DOI: 10.1109/NOSDAV.1997.629378

Tan, T.H., S.W. Chang and C.H. Yang, 2003. Performance evaluation and improvement of speaker recognition over GSM environment. Proceedings of the 37th IEEE International Carnahan Conference on Security Technology, Oct. 14-16, IEEE Xplore Press, University of Technol., Taiwan, pp: 440-443. DOI: 10.1109/CCST.2003.1297600

Tunnicliffe, G.W., A. Sathyendran and A.R. Murch, 1997. Performance improvement in GSM networks due to slow frequency hopping. Proceedings of the IEEE 47th Vehicular Technology Conference, May 4-7, IEEE Xplore Press, Phoenix, AZ, USA., pp: 1857-1861. DOI: 10.1109/VETEC.1997.605880 